\title{
Aspectos lexicográficos de los términos texto, discurso y enunciado en los diccionarios generales
}

GÉRARD FERNÁNDEZ SMITH

Universidad de Cádiz

\section{INTRODUCCIÓN}

En el presente trabajo nos proponemos llevar a cabo un análisis del proceso de construcción de algunos conceptos fundamentales en el seno de la lingüística textual y discursiva, concretamente aquellos que se refieren a su objeto de estudio, para poner de manifiesto algunas de las razones por las que estos términos presentan en ocasiones límites difusos en cuanto a sus designaciones, así como también, a veces muy similares, a veces diferentes, conceptualizaciones ${ }^{1}$. Ahora bien, como es lógico algunas de esas unidades no son creaciones ex novo ni construcciones basadas en raíces grecolatinas (como es propio de la terminología científica), sino que son especializaciones terminológicas de voces patrimoniales de las lenguas (igualmente derivadas de esas mismas raíces), hecho especialmente significativo en el ámbito de la lingüística textual y discursiva, toda que vez que las corrientes de investigación que la conforman tratan con los aspectos más generales de la realidad material representada por el lenguaje y las lenguas, realidad que ha sido objeto de interés para pensadores, filósofos y humanistas de todas las épocas de la historia.

Para ello, traemos a colación un conjunto, creemos que representativo, de definiciones extraídas de diccionarios no terminológicos, sino generales, tanto normativos como de uso (incluyendo algunos diccionarios de lengua inglesa), compuestos en diferentes momentos históricos, con el fin de ilustrar cómo los conceptos más generalizados, o estándares si se quiere, de estas voces han ido, de alguna manera, filtrándose como marcas semánticas (y lexicográficas) en su progresiva especialización en el seno de la teoría del lenguaje, y cómo, de manera complementaria, estos repertorios normativos o generales, han reflejado a su vez los usos terminológicos que todo ese quehacer científico ponía en circulación, tanto de manera explícita, mediante el uso de las marcas

${ }^{1}$ Cf. la serie de artículos en los que Casas Gómez (1994; 1994-1995; 1995; 2006) dedica especial atención a diversos aspectos de la terminología en general y, sobre todo, también dentro de la propia ciencia lingüística en particular. 
lexicográficas apropiadas, como de manera implícita, como en ocasiones puede deducirse del contenido de las acepciones.

Así pues, centraremos nuestra atención en algunos términos fundamentales de la lingüística del texto y el análisis del discurso, como son texto, discurso, enunciado ${ }^{2}$ y algunos otros a los que necesariamente habremos de referirnos en nuestra discusión, y demostraremos que sus conceptualizaciones más generalizadas así como su uso terminológico se basa en un conjunto reducido de rasgos semánticos referidos fundamentalmente a los siguientes aspectos:

a) el carácter escrito u oral de los productos lingüísticos;

b) la tipología textual;

c) el concepto de «acto de habla» y los aspectos pragmáticos de la comunicación;

d) el concepto de «oración»; y

e) la cohesión y la coherencia.

\section{ASPECTOS ETIMOLÓGICOS DE LOS TÉRMINOS TEXTO, DISCURSO Y ENUNCIADO}

Como se sabe, el origen de estas formas es conocido y este suele retrotraerse al latín, concretamente a las formas verbales TĔX $\breve{R E ~ y ~ C U ̆ R R E ̆ R E, ~ r e s p e c t i v a m e n t e . ~ E n ~}$ particular, la aparición en español de texto se documenta ya desde el siglo XIV, como señala Bernárdez (1982: 77), siguiendo a Corominas, y sólo a partir de época reciente adquieren estas formas algún valor terminológico específico dentro de los estudios de crítica literaria y también de la ciencia lingüística.

2.1. Ahora bien, con el fin de fijar con mayor detalle esta cuestión, todavía sería posible que nos remontáramos un poco más atrás en el tiempo, concretamente, hasta el indoeuropeo, para lo cual nos serviremos del trabajo de Roberts y Pastor (1996). Estos autores recogen en su diccionario una hipotética raíz indoeuropea *teks-, con el sentido de 'tejer, fabricar', que supondría un origen común para todas las lenguas indoeurope-

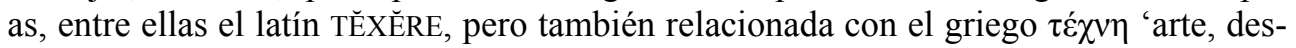
treza' (op. cit.: 178). Esta misma raíz sería origen además de términos relacionados como textura y contexto, entre otros. La expansión del significado de esta forma en latín es notable, como puede observarse en cualquiera de los numerosos diccionarios de latín de los que disponemos hoy en día. En ellos se recogen las siguientes traducciones, además de la mencionada 'tejer': a) 'entrelazar, trenzar'; b) 'hacer [entrelazando]'; c) 'hacer, construir', probablemente como confluencia con el otro significado que Roberts y Pastor proponen para la forma *teks-, 'fabricar', en indoeuropeo ${ }^{3}$, y formas derivadas

${ }^{2}$ Acerca de los conceptos designados por estos términos en relación con la lingüística del texto, puede encontrarse una síntesis muy útil en Loureda Lamas (2003: 20-24) y un análisis algo más detallado en Vitacolonna (1988).

${ }^{3}$ Concretamente, *teks-ōn-, con sufijo, 'tejedor, constructor', origen del griego $\tau \varepsilon ́ \kappa \tau \omega v$, 'carpintero, constructor', y de otras formas relacionadas, como tectónico, arquitecto, etc. 
como tectum, y, por último, d) 'escribir, componer [una obra literaria]', de donde pasaría a las lenguas romances con el significado de 'las palabras de un autor, a diferencia de las notas, glosas y comentarios', acepción que, con pocas modificaciones, hallaremos en todas las ediciones del Diccionario de la Real Academia Española (=DRAE) hasta la actualidad y en diccionarios de otras lenguas, como el Standard College Dictionary (=SCD) en inglés. En cuanto a discurso, Roberts y Pastor (1996: 84) proponen la forma *kers-, 'correr', que originaría los verbos latinos CŬRRĚRE y DISSCŬRRĔRE con adición del prefijo dis-. Este verbo de movimiento mantiene en latín el significado 'correr de una parte a otra, acudir', con un frecuentativo discurso, 'ir y venir, correr de un lado para otro'.

2.2. En lo que respecta al uso de estas formas en el romance castellano, la forma texto se documenta muy pronto, concretamente en el siglo XIV. Así, Corominas (1976, IV: 410) y Corominas y Pascual (1983, V: 450-451) la citan como un derivado de tejer (forma «general en todas las épocas y común a todos los romances»), tomado de těxtum, 'tejido', y documentada como testo (grafía que persiste durante mucho tiempo) en el Libro de Buen Amor, de Juan Ruiz, Arcipreste de Hita ${ }^{4}$. De la misma manera, el verbo discurrir (cf. Corominas, 1976, I: 913-914; Corominas y Pascual, 1983, II: 210), por su origen latino, aparece igualmente documentado en fechas tempranas, en Juan de Mena, el Marqués de Santillana y en el Vocabulario de Alonso de Palencia, con los significados 'correr acá y acullá' y 'tratar de algo'.

La forma discurso, procedente del latín DĬSCŬRSUS, -ŪS puede encontrarse concretamente en 1490, en el Vocabulario de Alonso de Palencia, pero en el sentido de 'curso de las aguas' (cf. Corominas y Pascual, 1983, II: 210). Por su parte, Juan de Valdés manifiesta su deseo de introducir esta forma, que ya es frecuente a partir de la segunda mitad del siglo XVI.

En cuanto al término enunciado, Corominas (1976, III: 534) y Corominas y Pascual (1983, IV: 251) señalan el carácter de cultismos que tienen las formas enunciación, enunciado y enunciativo, todas ellas derivadas del latín ENUNTIARE. Si bien puede encontrarse enunciación en Lope de Vega, no es hasta 1732 cuando aparece el verbo enunciar, en el Diccionario de Autoridades (=AUT). En este caso, la significación de ENUNTIARE, «exponer, divulgar, decir», ha permanecido inalterada desde su raíz latina, de manera que esta es la única de las formas comentadas que siempre designó una actividad verbal y que no sufrió, por tanto, un proceso de especialización anterior a la aparición de la lingüística como ciencia.

${ }^{4}$ Efectivamente, la forma alternativa testo se documenta entre 1330 y 1343 (no está clara la fecha original de redacción), en el Libro de Buen Amor de Juan Ruiz (1998). En el ejemplo, «Aquí fabla del pecado de la lujuria» (op. cit.: 159) puede leerse: «Non te quiero por vezino, nin me vengas tan presto; / al sabidor Virgilio, como dize en el testo, / engañó lo la dueña, quando lo colgó en el çesto, / coidando que lo sobía a su torre por esto». 


\section{NOCIONES DE LA LINGÜÍSTICA TEXTUAL Y DISCURSIVA EN DICCIONARIOS GE- NERALES DE LENGUA Y USO}

3.1. Así pues, una vez establecidos los orígenes de estos términos, creemos necesario partir de un repertorio lexicográfico más cercano a dichos orígenes, con el fin de ofrecer algunas de las definiciones que todavía pueden encontrarse en los diccionarios modernos, así como para documentar algunas de las ideas que sustentan nuestra argumentación en el presente trabajo. Así, por ejemplo, el primer testimonio en español de un diccionario normativo de la lengua, compuesto por la Real Academia Española en 1737, es el llamado Diccionario de Autoridades. Este aporta muchas de las acepciones que sin excesivas variaciones se han mantenido a lo largo de numerosas ediciones del $D R A E$, si bien, a buen seguro, no reflejan el verdadero uso que de estas voces hacen hoy los hablantes ${ }^{5}$. Así, el Diccionario de Autoridades (1737, VI: 266) define texto de la siguiente manera:

Las palabras propias de un autor, a distinción de las glosas, notas o comentarios que de ellas se hacen.

Se toma también por las palabras citadas de algún autor; y por antonomasia se toma por las sentencias de la Sagrada Escritura.

En este sentido, textual es «lo que conviene en el sentido con el texto, o es propio de él»y, además, «se aplica también al que autoriza sus pensamientos y los prueba con lo literal de los textos o expone un texto con otro».

Por otra parte, la forma discurso (op. cit., IV: 299) presenta numerosas acepciones relacionadas con el raciocinio y con la facultad de razonar. Sólo dos de ellas contienen alguna especificación relativa al lenguaje, pero, desde luego, resaltan tanto el carácter oral (por la referencia a la «plática» o «conversación») como escrito del mismo, además de que, y esto es importante, señalan la finalidad para la que es compuesto. Son las siguientes:

Vale también razonamiento, plática o conversación ponderada y dilatada sobre alguna materia.

Significa asimismo tratado o escrito que contiene varios pensamientos y reflexiones sobre alguna materia para persuadir o ponderar algún intento.

En cambio, la definición de enunciado (y formas relacionadas, como enunciar y enunciativo) (op. cit., III: 526) refleja un punto de vista heredado de la práctica de la retórica y la oratoria que podríamos vincular con el concepto manejado posteriormente en las gramáticas tradicionales, fuertemente influidas por el ámbito de la lógica. Así, enunciar se define como «declarar, manifestar, expresar, promulgar y dar a entender lo

\footnotetext{
${ }^{5}$ Véase, en este sentido, el trabajo de Muñoz López (1992: 122), quien recoge entre los usos poco frecuentes que documenta, la acepción del adjetivo discursivo referida a 'persona dada a discurrir', con los sinónimos meditabundo y reflexivo.
} 
que se ignora o está oculto. Es término usado en lo forense y tomado del latín enuntiare», de manera que enunciado es «lo así expresado, manifestado y declarado».

De las cuestiones tratadas hasta ahora se deduce que históricamente los términos discurso y enunciado han mantenido una designación relacionada con el campo de la actividad verbal, en cuanto que productos de la oralidad. Incluso, cuando el discurso puede entenderse como 'tratado o escrito', su definición apela a un contenido unitario (coherencia) y sujeto a una finalidad concreta (equiparable a la intencionalidad). En cambio, el término texto arrastra una conceptualización más bien formal, lo que aquí consideraremos como una definición instrumental o material, de ahí que su especialización se produjera en el campo de los estudios de filología y crítica textual, con la consiguiente adscripción al campo de la teoría de la literatura. Ello se debe, probablemente, a su origen en 'tejido', es decir, con la idea de 'trabazón', que prefigura una visión del texto como objeto que es vehículo de relaciones internas y que se concibe como totalidad. Asimismo, como se desprende de las acepciones más comunes, relacionadas en este caso con la «textualidad», puede inferirse una interpretación igualmente acorde con los intereses de aquellas disciplinas según la cual el texto es un producto encorsetado en el concepto de «autoría».

3.2. Mucho más útil resulta la observación de las acepciones que se registran en los diccionarios de lengua contemporáneos, especialmente en el diccionario normativo de la Real Academia de la Lengua Española ${ }^{7}$, pues además de que representan con mayor fidelidad el conocimiento tácito y generalizado de estos términos del que los hablantes disponen, reflejan paulatinamente, y en mayor o menor medida, los resultados logrados por la teoría del lenguaje y la teoría del texto. Ello es así en relación con algunas dis-

\footnotetext{
${ }^{6}$ Podría calificarse esta acotación como un tanto ingenua, en la medida en que Bernabé (1998: 313-315) se refiere, en relación con la etimología, a cierto procedimiento practicado en la Grecia Antigua y perpetuado durante siglos, basado en la búsqueda intencional del reflejo de la realidad en los hechos lingüísticos a través de pretendidas relaciones entre los nombres de las cosas. En el caso que nos ocupa, la asociación ya no es directa, entre la palabra y la cosa, ni tampoco entre dos palabras, a partir de cuyos significados relacionados se pretende obtener un correlato en la realidad. La asociación viene motivada por la significación ya existente de 'tejido', por lo que su base real es metafórica (cf. Ullmann, 1962: 91-93) y, todo lo más, nos hallamos ante un ejemplo de expansión (como señalábamos en $\S 1$. a propósito de TEXŌ en latín) del significado de esta forma o de cambio semántico por asociación de sentidos basada en la semejanza, como lo denominaría Ullmann (1962: 212-218). El uso polisémico, en cuanto que fenómeno del discurso (cf. Muñoz Núñez, 1999), si como tal uso podemos considerar la plurisignificación de esta forma, procede de las asociaciones que los propios hablantes establecen convencionalmente y refleja el principio de economía del lenguaje (cf. Paredes Duarte, 2007-2008, para una revisión actualizada de este principio).

${ }^{7}$ Empleamos las acepciones recogidas en el DRAE en sus ediciones de 1970, 1984, 1992 y 2001 (incluido el avance de la $23^{\mathrm{a}}$ ed. que puede consultarse on line en la página de la Real Academia de la Lengua). Inicialmente se observan pocos cambios en la mayoría de las acepciones de las sucesivas ediciones del diccionario. Sin embargo, a partir de la $21^{\mathrm{a}}$ ed. (1992) (antes en la edición de 1984 para el caso de enunciado) comienzan a aparecer marcas terminológicas e información específica propia de las disciplinas lingüísticas y de la teoría de la literatura.
} 
tinciones llevadas a cabo, especialmente, entre la escritura y la oralidad $^{8}$, que se identifican respectivamente con los términos del par texto / discurso. Descartamos, ahora sí, las acepciones referidas al concepto gráfico, material, de «texto», es decir, como 'cuerpo del texto' independiente de notas, comentarios y glosas, que suponen, por ejemplo, el grueso de dicha entrada léxica en la edición de 1970 del $D R A E$ o en las ediciones del Diccionario de uso del español (=DUE) de Ma Moliner (1966-1967; 2007), y que aparecen entre las acepciones de la misma unidad léxica en inglés (cf. Webster's New Collegiate Dictionary (1956) (=WCD), Standard College Dictionary (1963), Longman Dictionary of Contemporary English (1978) (=LDCE) y The American Heritage Dictionary of the English Language (1992) (=AHD), o que incluso pueden hallarse implícitas en un repertorio como el de Doezis (1990: 482), en el que párrafo es sinónimo de texto, en clara referencia a la extensión del mismo, que, dicho sea de paso, remite a una conceptualización formal o material del texto presente en la bibliografía especializada y que conlleva concepciones, en nuestra opinión desafortunadas, acerca de su mayor o menor longitud frente al discurso (cf. Stubbs, 1983: 10). En cambio, el DRAE (1984: 1306), en su acepción $5^{\mathrm{a}}$, ofrece una definición de la voz texto que da cuenta de su carácter terminológico 9 , que no establece distinciones entre las modalidades de uso y que la presenta como sinónimo de enunciado, si bien también remite a un concepto instrumental como es el de corpus (cf. Bernárdez, 1982: 78): «Enunciado o conjunto de enunciados orales o escritos que el lingüista somete a estudio».

Así pues, no existe, aparentemente, una distinción que se deba al canal lingüístico empleado en la transmisión del mismo, a diferencia de lo que se observa en el $D R A E$ (1992: 1399), en el que, además de la acepción anterior, aparece una primera según la cual texto es un «conjunto de palabras que componen un documento escrito». Igualmente, en el DUE, Moliner (1966-1967: 1305; 2007: 2866) presenta los siguientes usos, que avalan contundentemente lo expuesto:

a) Escrito cualquiera con cierto contenido.

b) Cualquier escrito a que alguien se refiere o cita.

c) Contenido de un escrito.

\footnotetext{
${ }^{8}$ Para una presentación detallada de las diferencias entre la lengua hablada y la lengua escrita, en el marco del análisis del discurso, véase Calsamiglia Blancafort y Tusón Valls (1999: 27-70 y 71-99). Cf. asimismo Brown y Yule (1983: 14-19).

9 Aunque no es nuestra intención extendernos en las debidas apreciaciones que la teoría lexicográfica actual aporta, sí nos parece oportuno resaltar los comentarios de Estopà (1998) en relación con el uso en los diccionarios de lengua de marcas terminológicas. Efectivamente, existen diferentes procedimientos para indicar el ámbito de uso temático de las voces terminológicas. La entrada en cuestión, cuando no se emplean abreviaturas y procedimientos tipográficos, representa un ejemplo de «expresión restrictiva» introducida en el cuerpo del texto mediante el uso de locativos (op. cit.: 379). Resultan, por otra parte, llamativas las apreciaciones acerca de la introducción paulatina de este tipo de marcas en los diccionarios, que se justifican por el hecho de que, además de las preferencias del lexicógrafo o lexicógrafos que componen el diccionario, estos se ven notablemente expuestos a las necesidades que los usuarios tienen en cada momento, que el lexicógrafo se ve obligado a satisfacer (op. cit.: 376). Dicho de otro modo, como ya señaló M $\mathrm{P}$. Battaner (apud R. Estopà), «la lexicografía va a la zaga, ofreciendo lo que los hablantes de una lengua ya han necesitado».
} 
En cambio, el Diccionario de español actual (=DEA) de Seco, Andrés y Ramos (1999: 1631), que define texto como «1 Enunciado escrito», y dentro de esta «b) Escrito considerado en su redacción original y auténtica. c) Pasaje citado de una obra escrita», incluye, a su vez, un uso terminológico muy similar al ya citado del $D R A E$, que nuevamente sitúa el texto como sinónimo de enunciado y que tampoco establece diferencias debidas a modalidades oral o escrita: «d) (Ling) Conjunto de signos, o enunciado, oral o escrito, considerado como objeto de estudio».

Por otra parte, siguiendo con la tendencia a igualar 'texto' y 'escritura' (en la que también podríamos adscribir lo que ya hemos anotado más arriba sobre el trabajo de Doezis), sin ser estrictamente un diccionario de lengua sino más bien un diccionario enciclopédico para estudiantes, el SCD (1963: 1386) recoge para el inglés algunas acepciones del correlato de texto en este idioma, text, como son las siguientes:

2. The actual or original words of an author

3. A written or printed version of the matter of an author's works: the folio text of Shakespeare

6. Any subject of discourse; a topic; a theme.

Las dos primeras obedecen al discurso referido, en la medida en que las palabras de otros son citadas a posteriori o presentadas bajo una versión nueva, pero llama la atención la acepción $6^{\mathrm{a}}$, por la implicación que esta tiene para una teoría del texto ${ }^{10}$. En efecto, existe una similitud con el concepto de «tópico de discurso», que no debe confundirse con la noción de «tema» preconizada desde la Escuela de Praga y la perspectiva funcional de la oración, y que ponemos en relación con algunas posturas que defienden, dentro de la lingüística del texto, una concepción del texto como entidad abstracta y descontextualizada cuya realización se debe al discurso. Asimismo, en dicho diccionario, hay una entrada para textual criticism en la que se observa la delimitación del objeto texto restringido al campo de los estudios literarios.

Finalmente, debe observarse con más detenimiento la última edición del $D R A E$, la de 2001 (versión on line en http://buscon.rae.es/draeI/), cuya primera acepción reza de la siguiente manera: «1. m. Enunciado o conjunto coherente de enunciados orales o escritos». En esta acepción, muy similar a la que acabamos de plasmar del $D E A$, además de la ya mencionada igualación con el término enunciado y la indistinción entre modalidades de uso, se recoge algún elemento procedente de la teoría del texto, como es la coherencia, aun cuando no se emplea una referencia mediante marca terminológica alguna, como si la continuidad de sentido haya llegado a ser ya una propiedad de lo dicho reconocida como tal por los hablantes, diríamos que dentro de su saber

\footnotetext{
${ }^{10}$ Esta acepción es común a todos los diccionarios de lengua inglesa analizados aquí. De hecho, hemos podido comprobar que existen más similitudes entre las definiciones halladas en estos diccionarios que entre las de los diccionarios compuestos en lengua española.
} 
elocucional (cf. Coseriu, 2008 ${ }^{11}$ : 141-142 y 144-145; 1992: 94-95 y 111-113; Vilarnovo, 1991: 130-134).

3.3. En cuanto a discurso, además de las acepciones correspondientes a la facultad de raciocinio, la reflexión y el uso de la razón que sirven de criterio para agruparlas, el $D R A E$ (1970: 484 y 1984: 505) recoge las siguientes (acepciones $6^{\mathrm{a}}$, $7^{\mathrm{a}}$ y $8^{\mathrm{a}}$, respectivamente):

6. Serie de las palabras y frases empleadas para manifestar lo que se piensa o siente.

7. Oración, palabra o conjunto de palabras con que se expresa un conjunto cabal.

8. Escrito de no mucha extensión, o tratado, en que se discute sobre una materia para enseñar o persuadir ${ }^{12}$.

De ellas se desprende la relación del término con algunas nociones de interés fundamental para las diferentes corrientes de análisis textual, que, a su vez, lo vinculan con la retórica, como son las finalidades inherentes a la producción de un texto determinado. Ciertamente, esta resulta ser una cuestión hoy en día apasionante para los especialistas, pues está directamente conectada con uno de los grandes aspectos que todavía quedan sin resolver en la teoría del texto: el de las tipologías textuales (cf. Schmidt, 1978: 52; Bernárdez, 1982: 219; Isenberg, 1987: 95; Loureda Lamas, 2003: 53). Así pues, es importante señalar cómo este diccionario de lengua recoge en su definición los fines o intencionalidades propias de un determinado tipo de texto, el discurso persuasivo o, técnicamente, el discurso argumentativo. En realidad, estamos ante una definición por metonimia de discurso, objeto que, como sabemos, no sólo trata de persuadir, sino que puede ser también vehículo de la explicación, la descripción, la conversación y la narración (según el repertorio propuesto, por ejemplo, por Bassols y Torrent, 1997, siguiendo a J.-M. Adam). También, por la mención de aspectos fundamentales para la teoría del texto, tal vez merecería mayor comentario la referencia, dentro de la acepción $7^{\mathrm{a}}$, al «conjunto cabal», que podríamos interpretar, nuevamente, en relación con la coherencia, de acuerdo con lo dicho más arriba (cf. el concepto de «discurso» en una gramática de corte tradicional como es la de Gili Gaya, 1970: 325).

Con todo, la siguiente edición del DRAE (1992: 537) aporta otras novedades, como son las acepciones $6^{\mathrm{a}}$ : «razonamiento o exposición sobre algún tema que se lee o pro-

${ }^{11}$ Hemos manejado esta edición para las referencias al trabajo de Coseriu (1980), sustancialmente mejorada y ampliada por Loureda Lamas, a partir de escritos posteriores del autor rumano y de reediciones y traducciones del texto original.

${ }^{12}$ Compárese esta última acepción con el avance de la $23^{\text {a }}$ edición del $D R A E$ (2001) que puede encontrarse en internet, en el que la misma cuenta ya con una marca terminológica que asocia el término y su definición a la teoría de la literatura, lo que sirve para constatar algunas de nuestras afirmaciones respecto a las conexiones entre esta disciplina y la teoría del texto (Fernández Smith, 2009). La acepción 9a define discurso como «9. m. T. lit. Escrito o tratado, generalmente de no mucha extensión, en que se discurre sobre una materia determinada». 
nuncia en público» (nótese el carácter oral que se le otorga al discurso ${ }^{13}$ ); y, especialmente, la $12^{\mathrm{a}}$, en la que hallamos un uso terminológico del término, según la cual este es sinónimo de enunciado, como ya lo era texto en las sucesivas ediciones de 1984, 1992 y 2001, además de que designa un concepto similar al de «habla» (parole), en la línea de algunos puntos de vista observables en el seno de corrientes de la lingüística textual y discursiva. En efecto, el DRAE define discurso como «Ling. Enunciado de la cadena hablada o escrita». Pues bien, en la edición de 2001, discurso ya no es sinónimo de enunciado (véase acepción $11^{\mathrm{a}}$ ) y, sin embargo, ahora lo es de oración (acepción $10^{\mathrm{a}}$ ): «10. m. Gram. oración (\| palabra o conjunto de palabras con sentido completo). 11. m. Ling. Cadena hablada o escrita». En realidad, esta acepción $10^{\mathrm{a}}$ recuerda, desde luego, a la afirmación de Gili Gaya (op. cit.), y también al «conjunto cabal» de la acepción $7^{\mathrm{a}}$ en $D R A E$ (1970: 484 y 1984: 505), que ahora es compuesta de manera más precisa, desde el punto de vista de la teoría lingüística. Sin embargo, este planteamiento podría entrar en conflicto con algunas diferenciaciones establecidas en la lingüística moderna entre los objetos «enunciado» y «oración», precisamente por lo que de materialización del sentido tiene el primero. Más aún, el avance de la $23^{\mathrm{a}}$ edición del $D R A E$ que puede hallarse en la consulta on line todavía añade más designaciones al término, vinculándolo con el estilo (en su acepción $8^{\mathrm{a}}$ ) y con la idea de proceso (habla efectivamente producida) a la que nos hemos referido anteriormente (en su acepción 12a). Asimismo, matiza la acepción $10^{\mathrm{a}}$ anterior, pero restringe el alcance del término discurso al despojarlo de la referencia al sentido y sustituirla por el mensaje. Tal proceder, aunque contrario a la teoría del texto comúnmente aceptada, no deja de ser un acierto si se considera que el discurso es un concepto gramatical (como estipulaba la marca terminológica original, si bien ahora se modifica) que es sinónimo de oración. Así pues, las novedades en el avance son:

8. m. Forma característica de plantear un asunto en un texto. Es un rasgo propio del discurso barojiano.

11. m. Ling. Unidad igual o superior a la oración formada por una sucesión de elementos con un principio y un final que constituye un mensaje.

12. m. Ling. Lenguaje en acción por oposición a las formas lingüísticas abstractas.

Desde luego, donde también encontramos algunos apuntes de interés para la concepción teórica de estos términos es en el uso de los términos en inglés. El SCD (1963: 380) ofrece como sinónimos de discourse los de speech y conversation, términos importantísimos en la orientación anglosajona de los estudios textuales y que conectan de manera directa las corrientes de análisis del discurso y de la conversación. En esta línea se sitúa la adscripción de una longitud determinada al discurso para distinguirlo del texto, a propósito de las opiniones vertidas por Stubbs (1983: 10) en relación con algu-

\footnotetext{
${ }^{13}$ Cf., en este sentido, los sinónimos propuestos por Doezis (1990: 165), peroración y arenga, claramente restringidos a la oralidad.
} 
nas consideraciones acerca de la distinción entre los términos tratados (cf., en este sentido, las definiciones propuestas por Richards, Platt y Platt, 1997: 107 y 254; Hickey, 1987: 8). Por tanto, dicho diccionario define discourse como: «2. A formal, extensive, oral or written treatment of a subject; a dissertation, treatise, sermon, etc.». Hallamos un concepto muy similar en otros diccionarios de lengua inglesa. Si bien en ellos no se detallan tanto las formas textuales (o géneros discursivos, si se quiere) en las que puede materializarse el discurso, sí que inciden en su carácter de [+interacción], ya que en todas ellas se asimila discourse a conversation, como puede observarse en el WCD (1956: 237) y en el $A H D$ (1992: 532), por ejemplo.

En cuanto al DUE (1966-1967: 1013), se recogen las siguientes acepciones para discurso:

a) En sentido amplio, conjunto de palabras con que alguien expresa lo que piensa, siente o quiere.

b) En sentido más restringido, exposición sobre un asunto serio hecha en tono ilustrativo por una persona a otras.

c) Particularmente, alocución, oración; exposición de su pensamiento que hace alguien en público con fines persuasivos.

d) También escrito dirigido a la gente o a ciertas personas en forma de discurso.

Las anteriores definiciones aparecen en la edición más reciente de este mismo repertorio como acepción $5^{\mathrm{a}}$, a la que se añade una nueva subacepción que da cuenta del uso terminológico del vocablo discurso (Moliner, 2007: 1056), de manera similar al $D R A E$ : «Unidad lingüística superior a la oración formada por un conjunto coherente de ellas». También aparece una acepción $6^{\mathrm{a}}$, «conjunto de opiniones o ideas que se expresan acerca de algo», que alude al contenido del mismo, a su unidad temática y, en parte, a sus fines comunicativos, de manera similar a otras acepciones halladas en este y en otros diccionarios como el DRAE relativas al contenido del texto.

Curiosamente, el contexto de uso que proporciona el DUE en su edición de 2007 como ejemplo para esta acepción, concretamente «Las fuerzas políticas han moderado su discurso después de las elecciones», se erigía en contenido semántico (o lexicográfico, al menos) en la definición aportada por el DEA (Seco, Andrés y Ramos, 1999: 1631), donde se lee «b) (Pol.) Conjunto de ideas que manifiesta un político o un grupo político», que acota la designación del mismo. Precisamente, este diccionario de uso proporciona más acotaciones de este tipo y mayor precisión en la información correspondiente al término, del que destacamos las siguientes:

4 Exposición amplia y formal sobre un tema determinado, pronunciada en público o destinada a ello. b) Exposición oral de cierta amplitud y generalmente de carácter aleccionador o persuasivo, que una persona dirige a otras personas.

5 (TLit) Escrito literario de carácter didáctico, que desarrolla un tema metódicamente. 
6 (Ling) Enunciado. b) Estilo (forma de la oración que depende de la manera de reproducir palabras o pensamientos ajenos o propios).

Como puede observarse, este repertorio refleja muy eficazmente los problemas propios de la conceptualización de estos términos, ya que prima el carácter [+oral] del discurso en su acepción $4^{\mathrm{a}}$, como en $D R A E$ (1992: 537), y restringe la marca [+escrito] al ámbito de la teoría de la literatura (acepción $5^{\mathrm{a}}$ ). Por otra parte, la acepción $6^{\mathrm{a}}$ refleja, si bien de forma un tanto más sucinta, el mismo concepto de «enunciado» que habíamos hallado como novedad en la acepción $12^{\mathrm{a}}$ de esa misma edición del DRAE (1992: 537).

De las definiciones comentadas se desprende del uso de los términos texto y discur$s o$, según la información hallada en el $D U E$ y en el $D E A$, una relación de carácter hiperonímico-hiponímico entre ellos, en función de la marca [ \pm oralidad], de manera que texto aparece en relación de inclusión con respecto a discurso. Dicho de otro modo, todo discurso puede ser [+oral] o, circunstancialmente, [+escrito], pero ningún texto es marcado [+oral]. La etiquetada como d) en el DUE supone, además, una definición circular o tautológica en la que se define un término haciendo uso del propio término en la definición, lo que avala nuestra opinión, pues en ella el discurso aparece como un tipo de escrito (compartirían determinadas características) o bien representa su contenido. Incluso una definición como la que aparece en el $D E A$, la número 4, sugiere la posibilidad de que el discurso pueda prepararse por escrito antes de ser expuesto oralmente.

Por otra parte, resulta igualmente llamativa la especialización a que se someten algunas acepciones del término, por cuanto este se identifica, en aquellas definiciones particulares, con un registro (recuérdese la acepción $8^{\mathrm{a}}$ del $D R A E 2001$ ) o construcción formal del lenguaje. Además de la aparición de formal en la definición del $S C D$, véase también el uso del mismo adjetivo en el DEA, el del adjetivo serio en el DUE y su correlato serious en el Longman Dictionary of Contemporary English (1978: 311), donde se define discourse como «a serious speech or piece of writing» y también como «serious conversation» (nótese la similitud entre discourse y conversation). Dicha especialización incide asimismo en los fines que las producciones verbales deben cumplir, etiquetados como persuasivos o tono ilustrativo en el DUE, carácter aleccionador, persuasivo o didáctico en el DEA, o enseñar y persuadir en el DRAE, y en la caracterización basada en el soporte formal o genérico que les sirve de vehículo, aspectos que con frecuencia interfieren y se relacionan en los intentos, por parte de los especialistas, de configurar tipos sistemáticos de texto, dentro del saber expresivo de los hablantes (cf. Loureda Lamas 2003: 17-19). Así, conviven en estos repertorios lexicográficos formas genéricas como dissertation, sermon o treatise, junto a estructuras textuales como la exposición e, implícitamente, la argumentación, cuyas distinciones se sustentan en el plano del contenido.

3.4. Finalmente, en relación con el término enunciado, que en lingüística se ha empleado en oposición a un concepto sintáctico como oración (cf. Brown y Yule, 1983: 19-20; Fuentes Rodríguez, 1996: 43; Loureda Lamas 2003: 24), el DRAE (1970: 546) remite a enunciación, definido como: «Acción y efecto de enunciar», pero, en cambio, a partir de su siguiente edición, se introduce en el DRAE (1984: 568) una novedad, 
además de la que ya hemos señalado con respecto a su uso en la definición de texto, puesto que recoge, por primera vez en el diccionario normativo de la lengua española, el uso terminológico del mismo y su relación con el concepto de «oración»: «Ling. En ciertas escuelas lingüísticas, secuencia finita de palabras delimitada por silencios muy marcados. Puede estar constituida por una o varias oraciones». En este sentido, con escasas modificaciones, la $22^{\mathrm{a}}$ edición del DRAE (2001) repite la primera acepción del término, pero, en cambio, acota en la segunda la marca terminológica: «2. m. Gram. Secuencia finita de palabras delimitada por pausas muy marcadas, que puede estar constituida por una o varias oraciones». No debe olvidarse en ningún momento que este término es tratado en las sucesivas ediciones del diccionario de la Academia como un sinónimo de texto, lo que puede darnos una idea aproximada de cuál es en teoría el conocimiento que los usuarios de la lengua tienen acerca de estas realidades. Por ello resulta ciertamente llamativo que esta definición de enunciado no sufra apenas modificaciones, mientras que la de texto, desprovista ya de toda marca terminológica refleja un contenido más cercano a la teoría del texto comúnmente aceptada, al incluir el concepto de «coherencia» en su acepción. Puede argumentarse que, con la acotación referida a la «gramática» en esta última definición de enunciado, se pretende dar cuenta del carácter interno del texto, de su gramaticalidad, de su cohesión, pero esto es sólo una suposición, toda vez que cada noción está vinculada a un término distinto.

En cuanto al DUE (1966-1967: 1153), este ya recoge un uso terminológico de enunciado, como puede verse en c):

a) Conjunto de palabras con que se enuncia una cosa.

b) Expresión con que se enuncia lo que se va a exponer.

c) También se ha propuesto este término por los gramáticos para designar una pieza o fragmento con unidad, de lenguaje.

Esta última subacepción, la más interesante para nuestros propósitos, ha sido sustituida en la versión más reciente de este diccionario (Moliner, 2007: 1199) por otra provista ahora de una marca de uso terminológico: «Ling. Manifestación lingüística de cualquier extensión». En esta nueva definición queda descartada la condición de «unidad»y, en cambio, se aproxima el concepto al de cadena lingüística, o manifestación del habla, como hemos observado en el análisis del término texto en las ediciones de 1984 y 2001 del $D R A E$, lo que refleja un cambio importante en el que se supone es el acervo común de los hablantes de español. En la misma línea, el DEA (Seco, Andrés y Ramos, 1999: 1874) define enunciado como «b) (Ling) Secuencia finita de palabras delimitada por silencios marcados», de manera similar al DRAE.

En lo que se refiere a la nómina de sinónimos, Doezis (1990: 194) ofrece, sin embargo, una visión más amplia de los fines e intenciones comunicativas, que vincula este concepto a la tipologización textual, al contemplar para el término enunciación los siguientes sinónimos: declaración, explicación y exposición, además de enunciado. 


\section{CONCLUSIONES}

Como conclusión, en lo que se refiere al origen de los términos texto y discurso y al uso que de ellos se hace en la lengua común, destaca una evidente contigüidad de sentido entre ellos, que hemos constatado tanto en español como en inglés. Esta contigüidad se basa en la existencia de marcas semánticas comunes (como 'productos lingüísticos' que son), así como en la indeterminación a la hora de adjudicar a los signos marcas específicas para realidades como la oralidad / escritura, la espontaneidad / no espontaneidad (que se observa en la inclusión de acepciones referidas a la presencia de registros formales o a un género de composición cualquiera), la interacción / no interacción (con frecuencia, el término discurso aparece definido como conversación, o acción similar), y otras de menor importancia como la extensión, que, desde luego, no facilitan en modo alguno su posterior distinción en el ámbito de la terminología lingüística. Es más, un resultado evidente de estas similitudes es que frecuentemente son considerados sinónimos precisamente en la especialidad en la que se emplean como tales términos, al contrario de lo que hemos podido observar en los repertorios generales consultados, donde en ningún caso las acepciones de texto y discurso hacen referencia la una a la otra.

Ahora bien, desde este punto de vista, y puesto que sólo en el caso del término discurso aparecen contenidos relativos a su teleología (cuando se habla de «persuasión», «tono ilustrativo», «carácter didáctico»), resulta, en nuestra opinión, patente cómo este concepto recubre más frecuentemente que el de «texto» aspectos pragmáticos de diversa índole en su uso terminológico en el seno de la teoría de la lingüística del texto y el análisis del discurso, si bien, y esto es contradictorio, son más frecuentes también en estos repertorios las sinonimias entre los términos texto y enunciado, cuando este último está más directamente conectado, creemos, con conceptos pragmáticos como el de «acto de habla», precisamente porque se opone a oración (el enunciado es al habla lo que la oración a la lengua). De la misma manera, son también numerosas las ocasiones en las que discurso es sinónimo de oración, lo que establece un paralelismo entre las series discursooración-lengua y texto-enunciado-habla difícilmente sostenible a la luz de la teoría lingüística actual. En aspectos como este nos basamos a la hora de señalar la indeterminación y los límites difusos que consideramos patentes en la información lexicográfica relativa a estos términos. Con todo, en los diccionarios de lengua inglesa sí hemos podido observar un planteamiento algo más coherente con este carácter pragmático del discurso, en tanto en cuanto la sinonimia se establece generalmente, casi sin excepciones, con términos próximos a la 'conversación', esto es, marcados como [+interacción]. Muy probablemente, ello es sólo otra prueba del carácter más heterogéneo y de los difusos límites que hemos observado en las definiciones de discurso, frente a las de texto, que implican en la mayoría de los casos algún tipo de restricción basada en unas acepciones muy concretas respecto al carácter material del mismo («cuerpo de un escrito», «párrafo», «las palabras de un autor», etc.).

Por todo ello, nos parecen muy destacables las numerosas relaciones de identidad e intersección que se establecen entre estos términos, en correlación con los avances que se van registrando en el seno de las teorías lingüísticas, de las que los diccionarios generales han ido convirtiéndose paulatinamente en reflejo. Así, el término texto suele restringirse a 
la modalidad «escrita», mientras que en las definiciones de discurso aparecen con frecuencia tanto su carácter «oral» como «escrito», lo que representa una cierta relación de inclusión. De la misma manera, también el discurso engloba al enunciado, no ya sólo por la mayor 'extensión' que en los diccionarios se otorga a ese concepto frente al otro, sino precisamente, y en consecuencia, por las numerosas ocasiones en que el discurso se define como un «enunciado o conjunto de enunciados», como ya hemos señalado con respecto a su sinonimia. Hay que destacar, eso sí, que los repertorios más modernos (como las ediciones de 1992 y 2001 del $D R A E$, o la del $D E A$ ), presentan criterios más precisos en sus definiciones, toda vez que se han ido generalizando marcas lexicográficas del tipo Ling., Gram., etc. que posibilitan un tratamiento más adecuado de los rasgos semánticos propios de estos usos terminológicos. En ediciones anteriores, como DRAE (1984) (aunque también en la edición de 2007 del $D U E$ ), donde no hay marcas explícitas, se ha recurrido a referencias al «lingüista» o a la «unidad lingüística» para determinar tales restricciones en el uso.

Puede afirmarse, finalmente, que el origen de estos términos, así como los usos y acepciones recogidos en los diccionarios a lo largo de la historia, han influido en mayor o menor grado en la configuración de conceptos muy importantes en el desarrollo de la lingüística moderna, especialmente en el marco de los estudios de lingüística textual y discursiva. De la misma manera, y esta es una conclusión fácilmente observable en relación con otros términos de la ciencia lingüística, también los repertorios léxicos generales, tanto normativos como de uso, han sido adaptados, ya en épocas más recientes, para reflejar con más o menos acierto el carácter terminológico de estas unidades léxicas, esto

es, su uso especializado en determinadas áreas de conocimiento y ámbitos profesionales, relacionados obviamente con el lenguaje y las lenguas.

\section{REFERENCIAS BIBLIOGRÁFICAS}

AA. VV. (1956): Webster's New Collegiate Dictionary, Springfield, G. \& C. Merriam. (1963): Standard College Dictionary, New York, Harcourt, Brace and World. (1978): Longman Dictionary of Contemporary English, Harlow, Longman.

(1992): The American Heritage Dictionary of the English Language, BostonNew York, Houghton Mifflin, $3^{\mathrm{a}}$ ed.

BAssols, Margarida y Ana María TORREnT (1997): Modelos textuales. Teoría y práctica, Barcelona, Octaedro. 
BERnABÉ, Alberto (1998): «Lingüística antes de la lingüística. La génesis de la indagación sobre el lenguaje en la Grecia Antigua», Revista Española de Lingüística, 28, 2, pp. 307-331.

BERNÁRDEZ, Enrique (1982): Introducción a la lingüística del texto, Madrid, Espasa-Calpe.

Brown, Gillian y George Yule (1983): Discourse analysis, Cambridge, Cambridge University Press.

Calsamiglia Blancafort, Helena y Amparo Tusón VAlls (1999): Las cosas del decir. Manual de análisis del discurso, Barcelona, Ariel.

CASAS Gómez, Miguel (1994): «Relaciones y principios lexemáticos en el ámbito de las terminologías», Pragmalingüistica, 2, pp. 79-122.

(1994-1995): «Hacia una caracterización semántica de la terminología lingüística», Estudios de Lingüistica, 10, pp. 45-65.

(1995): «En torno a algunos problemas semánticos de la terminología», Acta Universitatis Carolinae. Philologica 2. Translatologica Praguensia, VI, pp. 85-95.

(2006): «Contenidos actuales de la semántica léxica: la terminología», en W. Dietrich, U. Hoinkes, B. Roviró y M. Warnecke, eds., Lexikalische Semantik und Korpuslinguistik. Akten der Geckelergedenktagung, Tübinger Beiträge zur Linguistik, Band 490, Tübingen, Narr, pp. 13-40.

Corominas, Joan (1976 [1954]): Diccionario crítico etimológico de la lengua castellana, Madrid, Gredos, 4 vols.

- y José Antonio PASCUAL (1983): Diccionario crítico etimológico castellano e hispánico, Madrid, Gredos, 6 vols.

CoSERIU, Eugenio (1980): Textlinguistik: Eine einführung, edición de Jörn Albrecht, Tubinga, Gunter Narr.

(1992 [1988]): La competencia lingüística. Elementos de la teoría del hablar, elaborado y editado por H. Weber, versión española de F. Meno Blanco, Madrid, Gredos.

(2008): Lingüística del texto. Introducción a la hermenéutica del sentido, edición, anotación y estudio previo de Ó. Loureda Lamas. Madrid, Arco/libros.

DoEZIS, Miguel (1990): Diccionario de sinónimos, antónimos y parónimos, Madrid, Libsa, $4^{\mathrm{a}} \mathrm{ed}$. 
ESTOPÀ, Rosa (1998): «El léxico especializado en los diccionarios de lengua general: las marcas temáticas», Revista Española de Lingüística, 28, 2, pp. 359-387.

FERNÁNDEZ SMITH, Gérard (2009): «Antecedentes de la teoría lingüística del texto: bases conceptuales e históricas», en T. Bastardín Candón y M. Rivas Zancarrón, eds., Estudios de Historiografía Lingüística, Cádiz, Universidad de Cádiz, pp. 221-235.

FUENTES Rodríguez, Catalina (1996): Aproximación a la estructura del texto, Málaga, Ágora.

GILI GAYA, Samuel (1970 [1961]): Curso superior de sintaxis española, Barcelona, Bibliograf, $9^{\text {a }}$ ed.

HICKEY, Leo (1987): Curso de pragmaestilística, Madrid, Coloquio.

ISENBERG, Horst (1987): «Cuestiones fundamentales de tipología textual», en E. Bernárdez, ed., Lingüistica del texto, Madrid, Arco/Libros, pp. 95-129.

LOUREDA LAMAS, Óscar (2003): Introducción a la tipología textual, Madrid, Arco/Libros.

Moliner, María (1981): Diccionario de uso del español, 2 vols., Madrid, Gredos, [19661967].

(2007): Diccionario de uso del español, 2 vols., Madrid, Gredos, $3^{\mathrm{a}}$ ed.

MUÑOz LóPEZ, Elvira (1992): Diccionario de palabras olvidadas o de uso poco frecuente, Madrid, Paraninfo.

MuÑoz NúÑEZ, María Dolores (1999): La polisemia léxica, Cádiz, Universidad de Cádiz.

PAREDES DuARTE, María Jesús (2007-2008): «El principio de economía lingüística», Pragmalingüística, 15-16, pp. 166-178.

Real Academia Española (1984 [1737]): Diccionario de Autoridades. Diccionario de la lengua castellana, en que se explica el verdadero sentido de las voces, su naturaleza y calidad, con las phrases y modos de hablar, los proverbios o refranes, y otras cosas convenientes al uso de la lengua, edición facsímil, Madrid. Gredos.

(1970): Diccionario de la Lengua Española, Madrid, Espasa-Calpe, $19^{\mathrm{a}} \mathrm{ed}$.

(1984): Diccionario de la Lengua Española, Madrid, Espasa-Calpe, $20^{\mathrm{a}}$ ed.

(1992): Diccionario de la Lengua Española, Madrid, Espasa-Calpe, $21^{\mathrm{a}}$ ed.

(2001): Diccionario de la Lengua Española, Madrid, Espasa-Calpe, $22^{\mathrm{a}}$ ed. [hemos manejado la versión on line en http://buscon.rae.es/draeI/, que incluye avances de la $23^{\mathrm{a}}$ ed.]. 
Richards, Jack C., John Platt y Heidi Platt (1997 [1992]): Diccionario de lingüistica aplicada y enseñanza de lenguas, versión española de C. Muñoz Lahoz y C. Pérez Vidal, Barcelona, Ariel.

ROBERTS, Edward A. y Bárbara PASTOR (1996): Diccionario etimológico indoeuropeo de la lengua española, Madrid, Alianza.

RuIZ, Juan (1998): Libro de Buen Amor, edición, introducción y notas de G. B. GybbonMonypenny, Madrid, Castalia.

SECO, Manuel, dir., Olimpia de ANDRÉS y Gabino RAMOS (1999): Diccionario del español actual, Madrid, Aguilar, 2 vols.

SCHMIDT, Siegfried J. (1978): «Some Problems of Communicative Text Theories», W. U. Dressler (ed.), Current Trends in Textlinguistics, Research in Text Theory, 2, BerlinNew York, De Gruyter, pp. 47-60.

StubBS, Michael (1983): Discourse Analysis. The Sociolinguistic Analysis of Natural Language, Oxford, Basil Blackwell.

Ullmann, Stephen (1962): Semantics. An Introduction to the Science of Meaning, Oxford, Basil Blackwell.

VILARNOVO, Antonio (1991): «Teorías explicativas de la coherencia textual», Revista Española de Lingüística, 21, 1, pp. 125-144.

VitacolonnA, Luciano (1988): «'Text'/'Discourse’ Definitions», en J. S. Petöfi, ed., Text and Discourse Constitution, Research in Text Theory, 4, Berlin-New York, De Gruyter, pp. 421-439. 